\title{
МОДЕЛЮВАННЯ ПРОЦЕСУ БЕЗВІДХОДНОГО ВИДАВЛЮВАННЯ ДЕТАЛЕЙ ТИПУ ВТУЛОК
}

Розвиток машинобудування в сучасних умовах нерозривно пов'язаний з удосконаленням технологій. У машинобудуванні для виготовлення деталей це пов'язано з покращенням формоутворення заготовок - максимальним наближенням їх до форми деталі та підвищенням механічних властивостей отриманих деталей.

Для виконання таких завдань у заготівельному виробництві перспективними є процеси об'ємного штампування, зокрема точного об'ємного штампування (ТОШ). Ці процеси дозволяють отримувати деталі з мінімальними припусками на механообробку, зі сприятливим розташування волокон матеріалу в тілі деталі, що підвищує механічні властивості та строк служби деталей. Крім того, у процесів обробки тиском можливо отримувати деталі як простої форми, так і складнопрофільовані. Все це дозволяє заощадити енергетичні, матеріальні та трудові ресурсів [1,2].

Деталі $з$ наскрізним отвором (деталі типу втулок і кілець) широко застосовують практично у всіх галузях машинобудування та приладобудування. Однією з головних проблем виготовлення деталей з наскрізним отвором $є$ отримання високої якості продукції з одночасно високими показниками використання металу, продуктивності та низької собівартості виробу [3, 4].

Способи отримання деталей типу втулки різні: відрізання труби на заготовки з наступною механічною обробкою (за необхідністю); холодне видавлювання деталі типу стакан з наступним пробиванням перетинки; пряме або радіальне видавлювання з трубчастих заготовок [5-10].

Такі технології не забезпечують необхідну якість і точність виготовленого виробу. На місці перетинки залишаються задирки у вигляді кільцевого паска, а сама перетинка йде у відхід, що значно знижує коефіцієнт використання металу. Операція розділення металу передбачає розріз одержуваних у процесі видавлювання волокон металу в місці відділення перетинки, тому втулки отримані таких способом мають вихід волокон на внутрішню поверхню деталі, що значно знижує зносостійкість деталі. А використання трубних заготовок при штампуванні порожнистих виробів не має широкого використання за рахунок обмеженої номенклатури і великої вартості труб (на 40-70 \% вище вартості сортового прокату) $[9,10]$.

Тому доцільна розробка і використання безвідходного виробництва виробів 3 наскрізним отвором.

Для виготовлення деталей типу втулок відомий безвідходним спосіб - наскрізне прошивання $[11,12]$. Однак обмежене впровадження цього способу пов'язано з недостатнім вивченням процесу та його можливостей.

Метою роботи є дослідження енергосилового режиму наскрізного прошивання, визначення оптимальної форми деформуючого інструменту.

Для визначення енергосилового режиму наскрізного прошивання, визначення розмірів осередку деформації у процесі наскрізного прошивання використовувся метод верхньої оцінки (MBO). Основними припущеннями цього методу є: ідеальне жорстко-пластичне тіло; матеріал ізотропний; процес встановився у даний момент, розвантаження немає; напруження тертя постійне і задано законом Зібеля:

$$
\tau_{k}=2 \cdot \mu \cdot K
$$

де $K$ - постійна пластичності, МПа; $K=\frac{\sigma_{s}}{\sqrt{3}}$, 
$\sigma_{s}-$ напруження течії металу, МПа;

$\mu$ - коефіцієнт тертя.

Розглядалось декілька розбивок осередку деформації на жорсткі блоки (плоска задача). Розрахункові схеми й годографи швидкостей представлені на рис. 1.

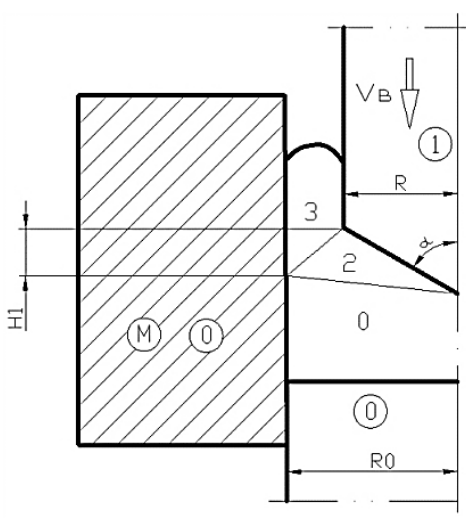

$\mathrm{a}$

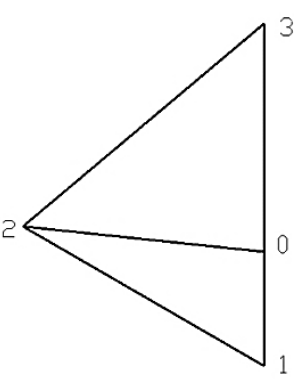

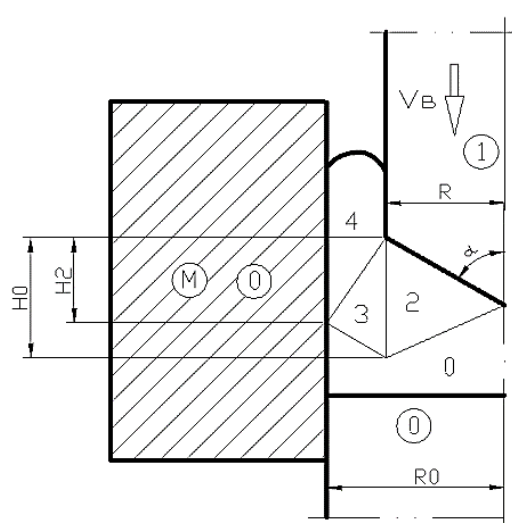

6
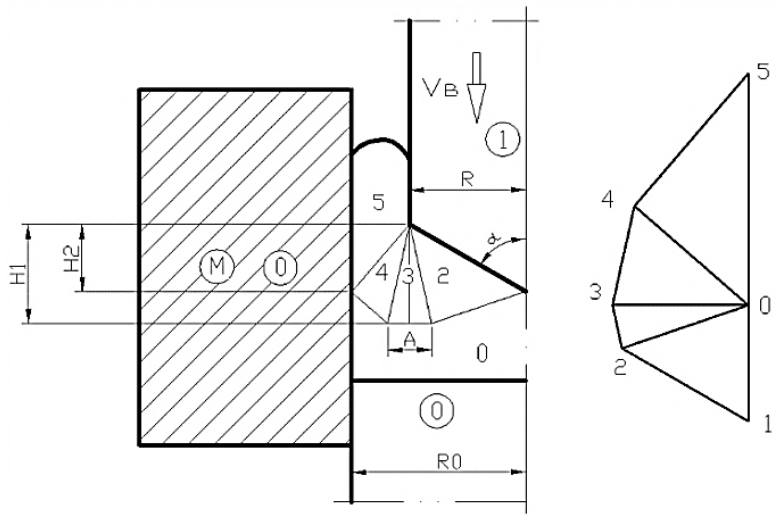

B

Рис. 1. Розрахункові схеми й годографи швидкостей для дослідження силового режиму процесу наскрізного прошивання при розбиванні осередку деформації на:

$\mathrm{a}-1$ жорсткий блок; б - 2 жорстких блоки; в - 3 жорстких блоки

Для визначення впливу геометричних параметрів процесу на питоме зусилля використовувалась формула рівності потужності зовнішніх і внутрішніх сил:

$$
\bar{p}=\frac{P}{K}=\frac{1}{2 R V_{0}}\left[\sum l_{i j} V_{i j}+2 \mu \sum l_{i j} V_{i j}\right],
$$

де $V_{0}$ - швидкість руху деформуючого пуансона; $R$ - радіус деформуючого пуансона; $l_{i j}$ - довжини ліній меж жорстких блоків; $V_{i j}$ - швидкості відносного переміщення жорстких блоків.

Довжини ліній меж жорстких блоків визначали через відомі геометричні параметри процесу, такі як: радіус пуансону, радіус заготовки та кут конусності торця пуансона. А швидкості переміщення жорстких блоків відносно один одного визначались через подібність трикутників розбивання осередку деформації та годографа швидкостей. Після підстановки отриманих виразів у формулу (1) та нескладних математичних перетворень були отримані формули для визначення приведеного тиску для кожного розбивання осередку деформації. Після цього були визначені вирази для визначення геометричних розмірів осередку деформації та оптимальні значення кута конусності торця пуансона. Для зручності усі параметри були віднесені до радіусу заготовки $R_{0}$. 
Розрахункові формули для визначення приведеного тиску наскрізного прошивання та геометричних параметрів осередку деформації при розбиванні на:

- 1 жорсткий блок:

Приведений тиск:

$$
\bar{p}=\frac{1}{\bar{R}}\left[\sqrt{\frac{2\left(\bar{H}^{2}+\bar{R}^{2}\right)(2-\bar{R})(1+\bar{R}(\mu-0,5))}{(1-\bar{R})}}+2 \bar{H}\right],
$$

де $\bar{H}=\frac{\bar{R}}{\operatorname{tg}(\alpha)} ; \bar{R}-$ відносний радіус пуансона; $2 \alpha-$ кут при вершині торця пуансона (кут конусності торця пуансона).

Оптимальний кут конусності торця пуансона:

$$
\alpha=\operatorname{arctg}\left(2 \bar{R} \sqrt{\frac{\bar{R}(1-\bar{R})}{\bar{R}+2 \mu(2-\bar{R})}}\right) .
$$

Висота осередку деформації:

$$
\bar{H}_{1}=\frac{1}{\bar{R}}\left[\sqrt{\frac{2\left(\bar{H}^{2}+\bar{R}^{2}\right)(1-\bar{R})(1+\bar{R}(\mu-0,5))}{(2-\bar{R})}}-1\right]+1 .
$$

- 2 жорстких блока:

Приведений тиск:

$$
\bar{p}=\frac{1}{2 \bar{R}}\left[\sqrt{\frac{(16-9 \bar{R}) \bar{H}^{2}+\bar{R}(2-\bar{R})+2 \mu\left(\bar{H}^{2}+\bar{R}^{2}\right)}{2(1-\bar{R})}}-3 \bar{H}\right] .
$$

Оптимальний кут конусності торця пуансона:

$$
\alpha=\operatorname{arctg}\left(3 \sqrt{\left.\frac{2 \bar{R}(1-\bar{R})(2+\bar{R}(2 \mu-1))}{(1+2 \mu)((9 \bar{R}-2)(1-2 \mu)+28 \mu}\right]} .\right.
$$

Висоти осередку деформації (див. рис. 1, схема в):

$$
\bar{H}_{2}=3 \sqrt{\frac{\bar{R}(1-\bar{R})(2 \mu+1)(2+\bar{R}(2 \mu-1))}{2[(9 \bar{R}-2)(1-2 \mu)+28 \mu]}} ; \bar{H}_{0}=2 \sqrt{\frac{2 \bar{R}(1-\bar{R})(2 \mu+1)(2+\bar{R}(2 \mu-1))}{(9 \bar{R}-2)(1-2 \mu)+28 \mu}} .
$$

- 3 жорстких блока:

Приведений тиск:

$$
\begin{aligned}
& \bar{p}=\bar{A}+\frac{2 \bar{H}_{1}\left[2\left(\bar{H}-\bar{H}_{1}\right)\left(\bar{H}-2 \bar{H}_{1}\right)+2 \bar{R}^{2}+\bar{A}(\bar{A}-\bar{R})\right]}{\left(\overline{H A}-2 \bar{H}_{1} \bar{R}\right)}+ \\
& +\frac{0,5\left(\bar{H}_{2}-\bar{H}_{1}\right)\left(0,25 \bar{A}^{2}-\bar{H}_{2}\right)}{\left.\bar{H}_{1}\left(1-\bar{R}^{2}\right) \bar{H}_{2}+1-0,5 \bar{A}-\bar{R}\right]}+\frac{3-1,5(1-\bar{R})^{2}+0,5 \bar{A}(5-6 \bar{R})}{(1-R)\left(\bar{H}_{2}+1-0,5 \bar{A}-\bar{R}\right)}+. \\
& +\frac{4 \mu \bar{H}_{1}\left(\bar{H}_{1}^{2}+\bar{R}^{2}\right)(2 \bar{R}-\bar{A})}{\bar{R}\left(\overline{H A}-2 \bar{H}_{1} \bar{R}\right)}
\end{aligned}
$$


Однак, оптимальний кут при вершині пуансона та геометричні параметри осередку деформації при розбиванні осередку на 3 жорстких блоки визначаються параметрично для кожного випадку окремо. Це пов'язане з неможливістю визначення екстремальних значень параметрів $\bar{H}_{1}, \bar{H}_{2}$ та $A$ функції приведеного тиску.

Встановлено, що при збільшенні коефіцієнту тертя $\mu$ від 0 до 0,5 значення оптимального кута конусності торця пуансона $\alpha$ збільшується (рис. 2), наприклад, при співвідношенні $R_{0} / R=1,5$ (ступінь деформації $\varepsilon=0,56$ ) від $30^{\circ}$ до 52. При збільшенні ступеня деформації (зменшенні співвідношення $R_{0} / R$ ) оптимальний кут конусності торця пуансона зменшується.

Оптимальний кут конусності торця пуансона при коефіцієнті тертя 0,08 знаходиться у межах $25^{\circ} \leq \alpha \leq 56^{\circ}$ (рис. 3). I зі збільшенням співвідношення $R_{0} / R$ від 1,88 до 1,15 (зі збільшенням ступеня деформації заготовки) кут конусності збільшується. Так, наприклад, при співвідношенні $R_{0} / R=1,15$ (ступінь деформації $\varepsilon=0,25$ ) оптимальний кут конусності становить $\alpha=56^{\circ}$, а при $R_{0} / R=1,36(\varepsilon=0,46)-\alpha=40^{\circ}$.

Встановлено, що зміна приведеного тиску від кута конусності торця пуансона має такий же характер, як і для пуансона $з$ плоским торцем (рис. 4). Але при використанні останнього приведений тиск збільшується на 27-55 \%. Тому з точки зору зниження зусиль деформування рекомендовано використовувати конусний пуансон з кутом при вершині $2 \alpha=120^{\circ}$ при співвідношенні $R_{0} / R<1,22$ ( $\bar{p}$ при цьому змінюється від 2,6 до 2,8); при співвідношенні $1,22 \leq R_{0} / R \leq 1,36$ кут при вершині $2 \alpha=90^{\circ}$, а при $R_{0} / R>1,36$ кут при вершині $2 \alpha=60^{\circ}$.

Для визначення оптимальної кількості жорстких блоків у осередку деформації при наскрізному прошиванні досліджувався вплив розбивання на приведений тиск процесу (рис. 5). Встановлено, що при коефіцієнті тертя $\mu=0,08$ (при холодному штампуванні) і куті конусності пуансона $\alpha=60^{0}$ у межах $R_{0} / R \leq 1,15 . . .1,3$ оптимальним є розбивання осередку деформації на 2 жорстких блоку, а при $R_{0} / R>1,3$ - розбивання на 3 жорстких блоку. Використання 1 жорсткого блоку при розбиванні осередку деформації дає завищене значення приведеного тиску: при $R_{0} / R<1,3$ до $3,5 \ldots 6$ \% від оптимального розбивання осередку деформації, а при $R_{0} / R>1,3$ до $20 \%$.

Процес наскрізного прошивання також було досліджено методом скінчених елементів (MCK) для сплаву АД1. Деформування відбувалось конусним пуансоном з кутом при вершині $2 \alpha=120^{\circ}$ трьох заготовок з плоскими торцями (рис. 6). Для процесу наскрізного прошивання можна виділити декілька стадій процесу (рис. 7). Перша стадія - початок видавлювання, встановлення процесу, при цьому питомий тиск стрімко зростає. Друга стадія - встановлений процесу прошивання першої заготовки. Питомий тиск досягає певного значення і не змінюється деякий час, який залежить від товщини заготовки (на графіку утворюється так зване плато). Наприкінці цієї стадії спостерігається зниження питомого тиску процесу (на 35-50 \%). Це пояснюється тим, що у цей час починається розділення донної частини заготовки (виникнення тріщин), а саме, утворення наскрізного отвору в деталі типу втулка. Але у цей самий час пуансон конусною частиною торця занурюється у другу (наступну) заготовку, тому питомий тиск не досягає нуля. I питомий тиск знов починає зростати (початок третьої стадії процесу), досягає певного значення і не змінюється деякий час, як і для попередньої заготовки. I знов наприкінці прошивання цієї заготовки спостерігається зниження питомого тиску, що пояснюється такими ж процесами у заготовці, що і у першої. Далі характер зміни питомого тиску наскрізного прошивання повторюється починаючи з третьої стадії, кількість таких циклів залежить від кількості заготовок, що прошиваються. 


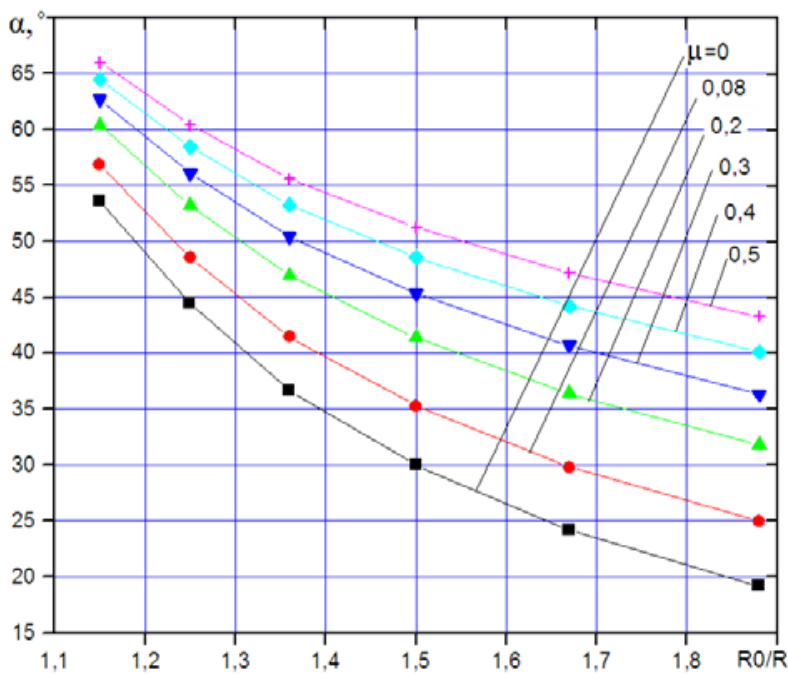

Рис. 2. Графік залежності оптимального кута конусності торця пуансона $\alpha$ від співвідношення геометричних параметрів процесу та коефіцієнту тертя

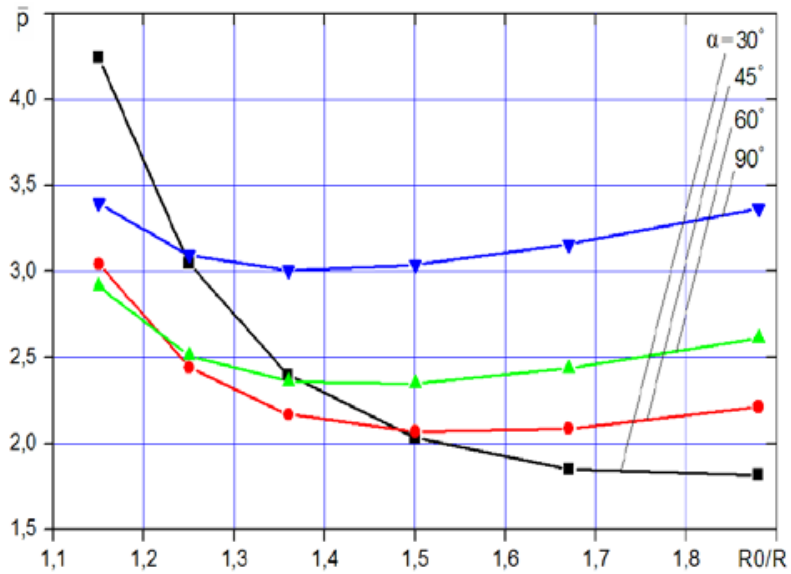

Рис. 4. Графік залежності приведеного тиску від геометричних параметрів процесу при різному коефіцієнті тертя

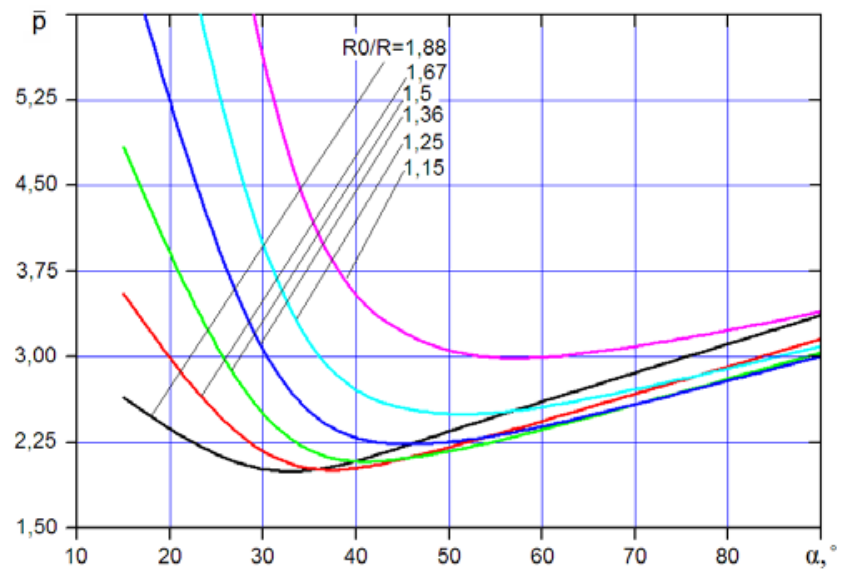

Рис. 3. Графік залежності приведеного тиску від кута конусності торця пуансона $\alpha$ при різному

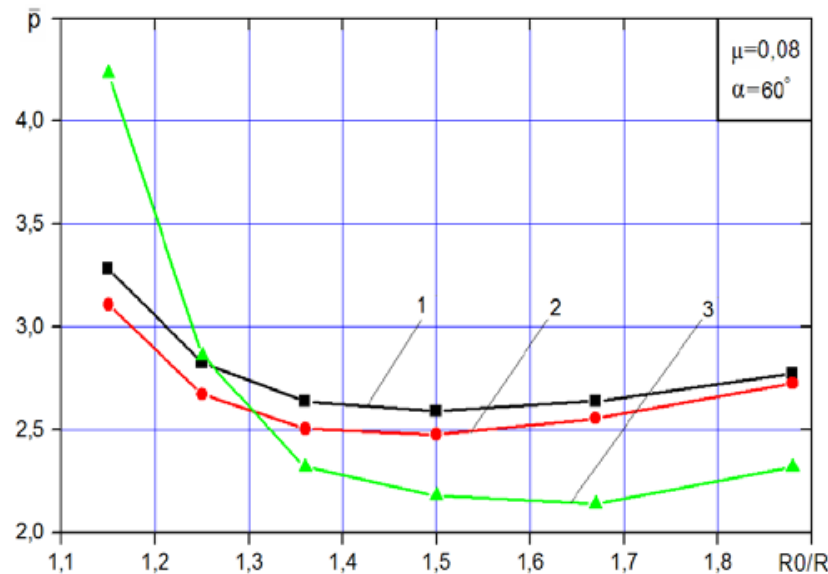

Рис. 5. Графік залежності приведеного тиску від геометричних параметрів процесу і кількості жорстких блоків при розбиванні осередку деформації: 1, 2, 3 - 1, 2, 3 жорстких блока відповідно

Встановлено, що для сплаву АД1 максимальний питомий тиск становить 410 МПа на перший стадії, але вже на третій стадії становить 384 МПа. Крім того, значення питомого тиску мало залежить від ступеня деформації. При збільшенні ступеня деформації (зменшенні співвідношення $R_{0} / R$ ) питомий тиску процесу наскрізного прошивання збільшується, але не суттєво.

Встановлено, що для сплаву АД1 і для ступенів деформації у межах 0,18-0,7 (співвідношення $R_{0} / R=1,1 \ldots 1,8$ ) метод скінчених елементів дає вище значення питомого тиску деформування на 35-40 \% у порівнянні з МВО (оптимальним розбиттям осередку деформації) (рис. 8). 


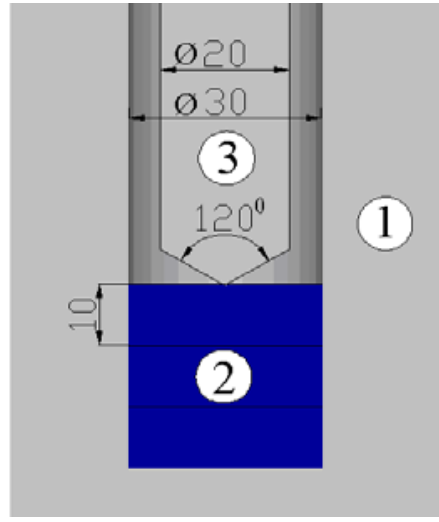

Рис. 6. Розрахункова схема наскрізного прошивання методом МСК

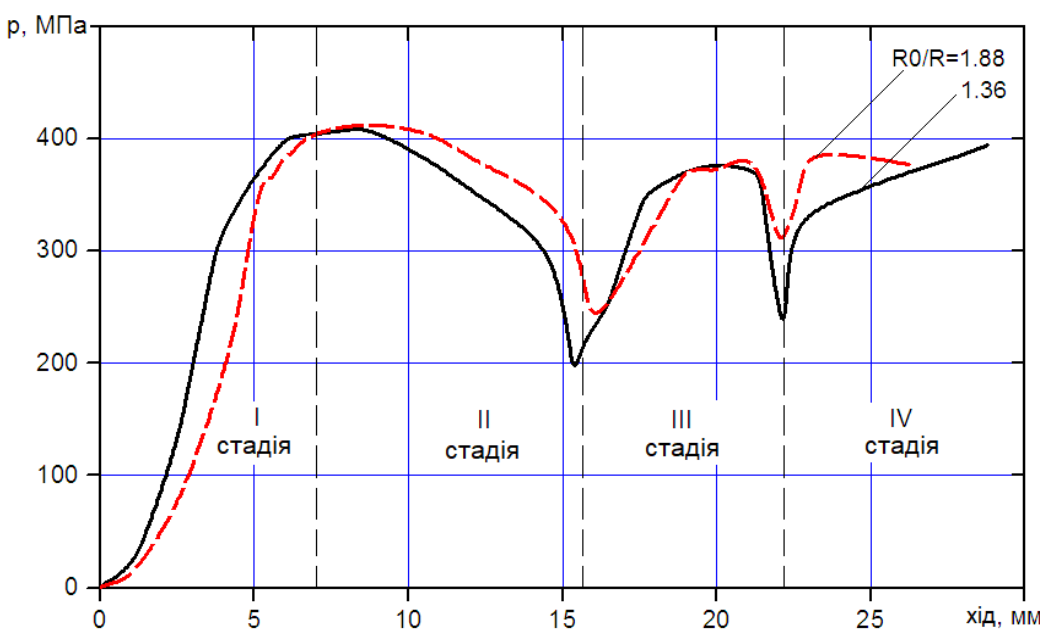

Рис. 7. Графік залежності питомого тиску від ходу пуансона для сплаву АД1

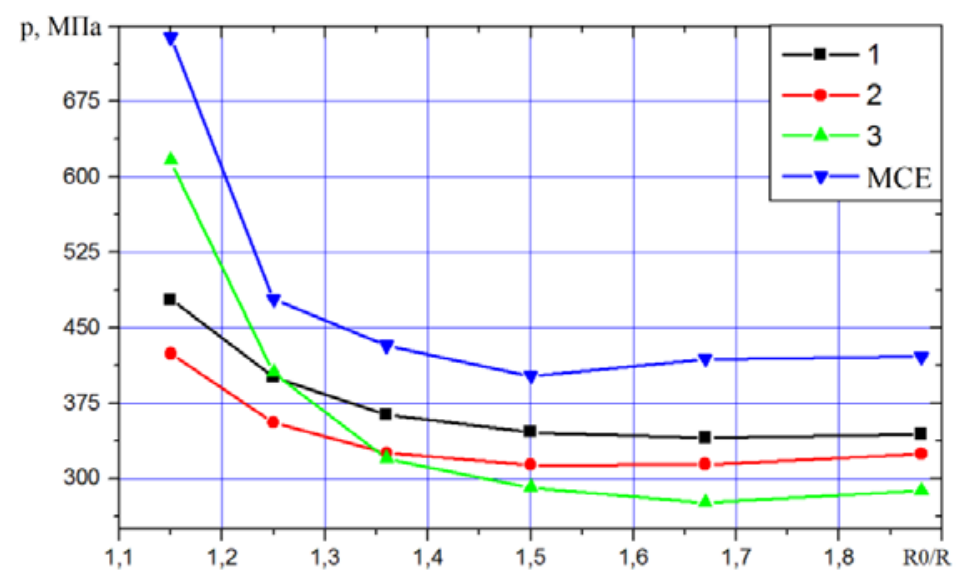

Рис. 8. Графік залежності тиску деформування сплаву АД1 методом скінчених елементів і методом верхньої оцінки при розбиванні осередку деформації на:

1, 2, 3 - 1, 2, 3 жорстких блока відповідно

\section{ВИСНОВКИ}

Аналіз отриманих графічних залежностей приведеного тиску від розбиття осередку деформації дозволив встановити, що оптимальною кількістю жорстких блоків в осередку деформації $є 2$ (для $\varepsilon \geq 0,6$ ) і 3 (для $\varepsilon<0,6$ ). Розбивання осередку деформації на 1 жорсткий блок дає завищене значення приведеного тиску у середньому $3,5 . .20$ \% у порівнянні з оптимальним. Використання рекомендованого кута конусності торця пуансона $\alpha=60^{\circ}$ при деформаціях $\varepsilon \leq 0,44$ і $\varepsilon \geq 0,67$ дає завищення приведеного тиску у середньому на $10 \ldots 37,5 \%$ від оптимального.

У результаті моделювання методом скінчених елементів встановлено, що у процесі наскрізного прошивання декількох заготовок деформуючий інструмент зазнає циклічних навантажень, різниця між максимальними та мінімальними значеннями тиску для сплаву АД1 складає 35-50 \%.

\section{СПИСОК ВИКОРИСТАНОЇ ЛІТЕРАТУРИ}

1. Ковка и штамповка: Справочник в 4-х. т. Москва: Машиностроение. 1986. Т.2. Горячая объемная штамповка. Под ред. Е. И. Семенова. 1986. 592 с.

2. Авдеев В. М., Аксенов Л. Б., Алиев И. С. и др. Изготовление заготовок и деталей пластическим деформированием; под ред. К. Н. Богоявленского, В. В. Риса. - Ленинград: Политехника, 1991. 351 с.

3. Алієв І. С. Методи пошуку нових технологічних способів видавлювання. Теорія та практика обробки матеріалів тиском : колективна монографія. Під ред.. Богуслаєва В. О., Бобиря М. І., Тітова В. А., Качана О. Я. Запоріжжя : АТ «МоторСіч». 2016. С. 364-385. 
4. Алиева Л. И. Совершенствование процессов комбинированного выдавливания: монография. Краматорск: ООО «Тираж - 51». 2018. 352 с. ISBN 978-966-379-846-2

5. Henry R., Liewald M. Numerical study of combined process of backward cup extrusion and piercing. Proceedings of the International Conference of global network for innovative technology (IGNITE-AICCE'17): 2017. AIP Conference Proceedings 1896(1):140007. DOI: 10.1063/1.5008163

6. Kalyuzhniy V. L., Aliieva L. I., Kartamyshev D. A., Savchinskii I.G. Simulation of cold Extrusion of hollow parts. Metallurgist. 2017, 61, 5-6, pp. 359-365. DOI: https://doi.org/10.1007/s11015-017-0501-1

7. Алієв I. С., Матвийчук В. А. Развитие локальных методов обработки металлов давлением. Обработка материалов давлением. Краматорск: ДГМА, 2008. 1(19). С. 201-204.

8. Лапин В. В., Фомичев А. Ф., Ермилов В. А., Якименко Б. М. Малоотходная технология изготовления полых деталей торцевой раскаткой. Кузнечно-штамповочное производство. 1985. 9. С. 18-20.

9. А. с. 732064 СССР, В21 J 5/10. Способ изготовления деталей типа втулок. Кузнецова Г.А., Кузнецов Г.В., Верзилов Ю.Н. и др. 1977.

10. А. с. 1052306 СССР, В 21 J 5/10. Способ изготовления деталей типа втулок. И.С. Алиев, В.В. Лапин. 1982.

11. Дмитриев А.М., Воронцов А.Л. Оценка нагрузки на инструмент при выдавливании изделий со сквозной ступенчатой полостью. Кузнечно-итамповочное производство. Обработка материалов давлением. 2002. 11. C. 21-28.

12. Бондарева Е. Н., Алиева Л.И. Малоотходные технологии изготовления втулок. Обработка материалов давлением. Краматорск: ДГМА. 2013.3 (36). С. 109-112.

13. Алиева Л. И., Картамышев Д. А., Махмудов К.Д. Комбинированное выдавливание-разделение деталей типа колец. Вісник НТУ «ХПІ». Харків. 2017. 43 (1265). С. 10-17.

\section{REFERENCES}

1. Forging and stamping. Handbook. In 4 t., T. 2. Hot stamping. Ed. Stmenov E.I. Moscow: Mechanical Engineering. 1987. 592 p. (in Russian).

2. Avdeev V.M., Aksenov L.B., Aliiev I.S. et al. Manufacturing of blanks and parts by plastic deformation. Eds. K.N.Bogoyavlenskiy, V.V.Ris. Leningrad: Polytechnic, 1991, 351 p. (in Russian).

3. Aliiev I.S. Methods of searching for new technological methods of extrusion. Theory and practice of material processing by pressure: a collective monograph. Eds. Boguslaev V.O., Bobir M.I., Titov V.A., Kachan O.Ya. Zaporizhia: Motor Sich JSC. 2016, pp. 364-385. (in Ukrainian).

4. Aliieva L.I. Improvement of combined extrusion processes: monograph. Kramatorsk: LLC "Tiraj - 51". 2018, 352 p. ISBN 978-966-379-846-2. (in Russian).

5. Henry R., Liewald M. Numerical study of combined process of backward cup extrusion and piercing. Proceedings of the International Conference of global network for innovative technology (IGNITE-AICCE'17): 2017. AIP Conference Proceedings 1896 (1):140007. DOI: 10.1063/1.5008163

6. Kalyuzhniy V.L., Alieva L.I., Kartamyshev D.A., Savchinskii I.G. Simulation of cold Extrusion of hollow parts. Metallurgist. 2017, 61, 5-6, pp. 359-365. DOI: https://doi.org/10.1007/s11015-017-0501-1

7. Aliiev I. S., Matviychuk V.A. Development of local methods of metal pressure treatment. Materials Working by Pressure. Kramatorsk: DSEA. 2008, 1 (19), pp. 201-204. (in Russian).

8. Lapin V.V., Fomichev A.F., Ermilov V.A., Yakimenko B.M. Low-waste technology for manufacturing hollow parts by end rolling.. Forging and stamping production. 1985. 9. P. 18-20. (in Russian).

9. Pat. 732064 USSR, B21 J 5/10. A method of manufacturing parts such as bushings. Kuznetsova G.A., Kuznetsov G.V., Verzilov Y.N. et al. 1977.

10. Pat. 1052306 USSR, B21 J 5/10. A method of manufacturing parts such as bushings. Aliiev I.S., Lapin V.V. 1982.

11. Dmitriyev A.M., Vorontsov A.L. Assessment of the load on the tool when extruding products with a through stepped cavity. Forging and stamping production. Materials Working by Pressure. 2002, 11. pp. 21-28. (in Russian).

12. Bondareva E.N., Aliieva L.I. Low-waste bushing manufacturing technologies. Materials Working by Pressure. Kramatorsk: DSEA. 2013, 3 (36), pp. 109-112. (in Russian).

13. Aliieva L.I. Kartamyshev D.A., Makhmudov K.D. Combined extrusion-separation of parts such as rings. Bulletin of NTU "KhPI". Kharkov. 2017, 43 (1265), pp. 10-17. (in Russian).

Бондарева О. М. - аспірант кафедри ОМТ ДДМА;

Корденко М. Ю. - аспірант кафедри ОМТ ДДМА;

Моісєєва А. М. - аспірант кафедри ОМТ ДДМА.

ДДМА - Донбаська державна машинобудівна академія, м. Краматорськ.

E-mail: omd@dgma.donetsk.ua 